\title{
Staphylococcus epidermidis biofilms with higher proportions of dormant bacteria induce a lower activation of murine macrophages
}

\section{Correspondence \\ Manuel Vilanova \\ vilanova@icbas.up.pt}

Received 7 March 2011

Accepted 22 July 2011
Filipe Cerca, ${ }^{1,2}$ Filipa Andrade, ${ }^{1}$ Ângela França, ${ }^{1,3}$

Elva Bonifácio Andrade, ${ }^{1,2}$ Adília Ribeiro, ${ }^{1}$ Agostinho A. Almeida, ${ }^{4}$

Nuno Cerca, ${ }^{3}$ Gerald Pier, $^{5}$ Joana Azeredo $^{3}$ and Manuel Vilanova ${ }^{1,2}$

${ }^{1}$ ICBAS - Instituto de Ciências Biomédicas de Abel Salazar, Largo do Professor Abel Salazar 2, 4099-003 Porto, Portugal

${ }^{2}$ IBMC - Instituto de Biologia Molecular e Celular, Rua do Campo Alegre 83, Porto, Portugal

${ }^{3}$ CEB-IBB, Campus de Gualtar, Universidade do Minho, $4710-057$ Braga, Portugal

${ }^{4}$ REQUIMTE, Departamento de Química-Física, Faculdade de Farmácia, Universidade do Porto, Rua Aníbal Cunha 164, 4099-030 Porto, Portugal

${ }^{5}$ Channing Laboratory, Department of Medicine, Brigham and Women's Hospital, Boston, MA 02115, USA

Staphylococcus epidermidis is an opportunistic pathogen and, due to its ability to establish biofilms, is a leading causative agent of indwelling medical device-associated infection. The presence of high amounts of dormant bacteria is a hallmark of biofilms, making them more tolerant to antimicrobials and to the host immune response. We observed that $S$. epidermidis biofilms grown in excess glucose accumulated high amounts of viable but non-culturable (VBNC) bacteria, as assessed by their low ratio of culturable bacteria over the number of viable bacteria. This effect, which was a consequence of the accumulation of acidic compounds due to glucose metabolism, was counteracted by high extracellular levels of calcium and magnesium added to the culture medium allowing modulation of the proportions of VBNC bacteria within S. epidermidis biofilms. Using bacterial inocula obtained from biofilms with high and low proportions of VBNC bacteria, their stimulatory effect on murine macrophages was evaluated in vitro and in vivo. The inoculum enriched in VBNC bacteria induced in vitro a lower production of tumour necrosis factor alpha, interleukin- 1 and interleukin- 6 by bone-marrow-derived murine macrophages and, in vivo, a lower stimulatory effect on peritoneal macrophages, assessed by increased surface expression of Gr1 and major histocompatibility complex class II molecules. Overall, these results show that environmental conditions, such as $\mathrm{pH}$ and extracellular levels of calcium and magnesium, can induce dormancy in S. epidermidis biofilms. Moreover, they show that bacterial suspensions enriched in dormant cells are less inflammatory, suggesting that dormancy can contribute to the immune evasion of biofilms.

\section{INTRODUCTION}

Staphylococcus epidermidis is among the most frequent opportunistic pathogens causing nosocomial infections and is the leading causative agent of medical deviceassociated infections (Vuong \& Otto, 2002). The ability to establish biofilms - multilayered bacterial communities stabilized by intercellular adhesive mechanisms (Costerton

Abbreviations: BMDM, bone-marrow-derived macrophage; FSC, forward scatter; IL, interleukin; MHC, major histocompatibility complex; $\mathrm{PI}$, propidium iodide; SSC, side scatter; TNF- $\alpha$, tumour necrosis factor alpha; VBNC, viable but non-culturable. et al., 1999; O'Toole et al., 2000) - has been considered the most important virulence factor of $S$. epidermidis (Costerton et al., 2003; Fux et al., 2005). Typical biofilm disease manifests with common features. Usually, the initial infection is not life threatening, but subsequent exacerbations may occur and often require the surgical removal of the infected tissue or medical device (Wolcott \& Ehrlich, 2008). Biofilms have a particular physiology, such as higher frequencies of dormant bacteria, that accounts for their ability to cause recalcitrant human infections (Lewis, 2007). The reversible state of low metabolic activity in which dormant bacteria can persist for extended periods 
without division (Kaprelyants et al., 1993) is considered their principal characteristic contributing to survival within infected hosts or tolerance to antimicrobials (Brown et al., 1988; Qu et al., 2010; Yao et al., 2005). In the present study we show that dormancy in established $S$. epidermidis biofilms can be modulated by glucose, calcium and magnesium levels. The possibility of modulating the proportions of dormant bacteria within biofilms allowed us to compare their inflammatory potential in vitro, in cultured murine macrophages, and in vivo, in peritoneal macrophages upon injection of biofilm cells.

\section{METHODS}

S. epidermidis biofilm cultures. The biofilm-forming strain $S$. epidermidis 9142 (Cerca et al., 2004) was used in this study. Tryptic soy broth (TSB; Merck) and tryptic soy agar (TSA; Merck) were prepared according to the manufacturer's instructions. S. epidermidis 9142 grown on TSA plates was used to inoculate $50 \mathrm{ml}$ TSB subsequently incubated at $37{ }^{\circ} \mathrm{C}$ in a shaker rotator at 80 r.p.m. for $18 \mathrm{~h}$. Cells were then harvested by centrifugation (10 min at $10500 \mathrm{~g}$ at $4{ }^{\circ} \mathrm{C}$ ), resuspended in PBS and the optical density at $640 \mathrm{~nm}$ was adjusted to $0.250( \pm 0.05)$. Then, $10 \mu \mathrm{l}$ of this bacterial suspension was transferred to a well of a polystyrene plate (Nunc) containing $1 \mathrm{ml}$ TSB supplemented with $0.3 \%(\mathrm{w} / \mathrm{v})$ glucose (Merck) (TSB $0.3 \% \mathrm{G}$ ), and incubated in a shaker rotator at $37{ }^{\circ} \mathrm{C}$ and 80 r.p.m. for 24 h so a biofilm could be established (Mack et al., 1992). The culture medium was then removed, and biofilms were allowed to grow for a further $24 \mathrm{~h}$ in: TSB, TSB supplemented with $10 \mathrm{mM}$ calcium chloride (Sigma) and $10 \mathrm{mM}$ magnesium chloride (Sigma) $\left(\mathrm{TSB}+\mathrm{Ca}^{2+} / \mathrm{Mg}^{2+}\right)$, TSB supplemented with $1 \%(\mathrm{w} / \mathrm{v})$ glucose (Merck) (TSB 1\%G), TSB 1\%G supplemented with $10 \mathrm{mM}$ calcium chloride (Merck) and $10 \mathrm{mM}$ magnesium chloride (Merck) (TSB $\left.1 \% \mathrm{G}+\mathrm{Ca}^{2+} / \mathrm{Mg}^{2+}\right)$, TSB with $\mathrm{pH}$ adjusted to 5.0 with hydrochloric acid (Merck) (TSB pH 5.0) or TSB $1 \%$ G supplemented with $100 \mathrm{mM}$ disodium hydrogen phosphate (Merck) (TSB $1 \% \mathrm{G}+\mathrm{HPO}_{4}{ }^{2-}$ ).

Quantification of live bacteria and cultivable bacteria within biofilms. S. epidermidis biofilms were carefully washed twice with $1 \mathrm{ml}$ PBS to remove planktonic cells in the culture supernatant. The biofilm was then mechanically disrupted in $1 \mathrm{ml}$ PBS and the resulting cell suspension was transferred to a polystyrene tube and sonicated on ice, at $18 \mathrm{~W}$ for $10 \mathrm{~s}$ (Branson sonicator). This treatment eliminated bacterial aggregates since flow cytometric signals with high forward scatter (FSC) and high side scatter (SSC) (corresponding to bacterial clumps) were absent after sonication. Moreover, this treatment did not affect cell membrane permeability, as determined by propidium iodide (PI) incorporation (data not shown). After vortexing, the bacterial suspensions were serially diluted in PBS and plated on TSA for quantification of the number of culturable bacteria. For the quantification of the number of live bacteria by flow cytometry, $30 \mu \mathrm{l}$ cell suspension was transferred to $270 \mu \mathrm{l}$ PBS containing $\left(5 \mu \mathrm{g} \mathrm{ml}^{-1}\right)$ PI (Sigma), SYBR-I (Invitrogen; 1:5000 commercial stock) and $3 \mu \mathrm{l}$ fluorescent counting beads (Invitrogen). Bacterial quantification was carried out using a FACScan (Becton Dickinson) containing a low-power air-cooled $15 \mathrm{~mW}$ blue $(488 \mathrm{~nm})$ argon laser. Data were acquired using CellQuest software (Becton Dickinson) and analysed using Flowjo 7.2.5 software (Tree Star).

Glucose, lactate, pH, calcium and magnesium level measurement. Established biofilms grown for $24 \mathrm{~h}$ were allowed to grow for an additional $24 \mathrm{~h}$ in TSB or TSB $1 \% \mathrm{G}$, as described above. At $3 \mathrm{~h}$ intervals, supernatant aliquots were removed, centrifuged at $20800 \mathrm{~g}$ for 5 min at $4{ }^{\circ} \mathrm{C}$ and stored at $-20{ }^{\circ} \mathrm{C}$ until use. Glucose and lactate concentrations were determined using commercially available quantification kits (R-Biopharm) according to the manufacturer's instructions. The supernatant $\mathrm{pH}$ was determined with a $\mathrm{pH}$ meter (WTW pH 330). Calcium and magnesium determinations were performed by flame (air/acetylene) atomic absorption spectrometry using a Perkin-Elmer model 5000 instrument (Perkin Elmer) operated according to the manufacturer's instructions. $\mathrm{Mg}^{2+}$ (Perkin Elmer) and $\mathrm{Ca}^{2+}$ (Pye Unicam) hollow cathode lamps were used as light sources. Before analysis, the supernatant samples were diluted 1:200 (for $\mathrm{Ca}^{2+}$ ) and 1:1000 (for $\mathrm{Mg}^{2+}$ ) with deionized water. For $\mathrm{Ca}^{2+}$ measurement, lanthanum $(0.5 \%)$ was also added.

Mice. Male $\mathrm{BALB} / \mathrm{c}$ mice $6-8$ weeks of age were purchased from Charles River and kept at the animal facilities of the Institute Abel Salazar (ICBAS, Portugal) during the experiments. Hiding and nesting materials were provided for enrichment. Procedures involving mice were performed according to the European Convention for the Protection of Vertebrate Animals used for Experimental and Other Scientific Purposes (ETS 123) and 86/609/EEC Directive and Portuguese rules (DL 129/92). Authorization to perform the experiments was issued by the competent national board (Direcção-Geral de Veterinária), document number 0420/000/000/2010.

\section{Infection of murine bone-marrow-derived macrophage (BMDM)} cell cultures. Mouse bone marrow cells were collected from femoral shafts by flushing with $3 \mathrm{ml}$ cold RPMI 1640 (Sigma). Adherent bone marrow cells were removed by incubation in RPMI 1640 (Sigma) supplemented with $0.05 \mathrm{M}$ 2-mercaptoethanol, 0.1 M HEPES buffer and $10 \%$ FBS (PAA) at $37{ }^{\circ} \mathrm{C}$ for $6 \mathrm{~h}$ in a sterile Petri dish. The nonadherent bone marrow cells were then distributed in 96-well plates in RPMI supplemented with $10 \%(\mathrm{v} / \mathrm{v})$ L929-cell conditioned medium (LCCM) for 8 days. At day 3, $10 \%(\mathrm{v} / \mathrm{v})$ LCCM was added to the cultures and at day 6 the culture medium was replaced. At day 8, BMDMs were stimulated with RPMI containing $1 \times 10^{4}$ live bacteria obtained from biofilms grown as indicated above. At $3 \mathrm{~h}$ intervals after BMDM challenge, $10 \mu \mathrm{l}$ culture supernatant was removed and cultured on TSA plates to determine bacterial growth. At $9 \mathrm{~h}$ post-stimulation, the culture supernatants were removed and stored at $-20{ }^{\circ} \mathrm{C}$ until use.

Evaluation of BMDM death following incubation with intact $\boldsymbol{S}$. epidermidis biofilms. Intact $S$. epidermidis biofilms grown as noted before were washed twice with $1 \mathrm{ml}$ RPMI and then $500 \mu \mathrm{l}$ RPMI containing $5 \times 10^{5}$ BMDMs was added. After $2 \mathrm{~h}$ incubation, BMDM and biofilm cells were resuspended in PBS, incubated with $\mathrm{PI}\left(5 \mu \mathrm{g} \mathrm{ml}^{-1}\right)$ and BMDM death ( $\mathrm{PI}^{+}$cells) was determined by flow cytometry.

Cytokine quantification. Tumour necrosis factor alpha (TNF- $\alpha$ ), interleukin-1 (IL-1) and interleukin-6 (IL-6) were quantified using commercially available quantification kits (eBioscience) according to the manufacturer's instructions.

Murine intra-peritoneal infection. Mice were infected intraperitoneally with $0.5 \mathrm{ml}$ sterile PBS or PBS containing $5 \times 10^{5}$ live bacteria obtained from $S$. epidermidis biofilms grown as indicated. After $6 \mathrm{~h}$, mice were sacrificed and the peritoneal cavity washed with $6 \mathrm{ml}$ cold sterile PBS. Peritoneal exudates were centrifuged at $1200 \mathrm{~g}$ for $5 \mathrm{~min}$ and the pellets resuspended in $500 \mu \mathrm{l}$ PBS containing $1 \%$ BSA (Sigma) and $10 \mathrm{mM}$ sodium azide (Sigma). The following mAbs were used for immunofluorescence cytometric analysis: fluorescein isothiocyanate (FITC) conjugated anti-mouse Ly-6G and Ly-6C (Gr1) (BD Pharmingen); phycoerythrin (PE) anti-mouse F4/80 (Biolegend); biotin-conjugated anti-mouse major histocompatibility complex (MHC) class II (Southern Biotechnology Associates) with Cy-Chrome-conjugated 
streptavidin (BD PharMingen). Mononuclear cells $\left(5 \times 10^{5}\right)$ were stained for each sample.

Statistical analysis. Quantitative assays were compared using the one-way analysis of variance (ANOVA) test using SPSS software (IBM).

\section{RESULTS AND DISCUSSION}

\section{Excess glucose induces dormancy in S. epidermidis biofilms}

A hallmark characteristic of biofilms is the presence of higher frequencies of dormant bacteria as compared with their respective exponential phase planktonic cultures (Brown et al., 1988). In this study we evaluated whether excess glucose in the culture medium, often used to induce planktonic bacteria to establish a biofilm community in vitro (Mack et al., 1992), could account for the induction of cell dormancy within S. epidermidis biofilms. Established biofilms were allowed to grow for an additional $24 \mathrm{~h}$ in TSB or TSB supplemented with $1 \%$ of glucose (TSB $1 \% \mathrm{G}$ ) and the proportions of dormant bacteria were then determined. According to published reports (Kaprelyants \& Kell, 1993; Shen et al., 2010; Shleeva et al., 2002), dormancy within S. epidermidis biofilms was evaluated by the ratio of the number of culturable bacteria over the number of viable bacteria (c.f.u./viable bacteria). Flow cytometry was used to quantify the number of viable bacteria, using a LIVE/DEAD stain (Ben-Amor et al., 2005; Saegeman et al., 2007), and the spread plate method was used to determine the number of culturable bacteria (c.f.u.) in the differently grown biofilms. As shown in Fig. 1(a), biofilms grown in TSB or TSB $1 \% \mathrm{G}$ presented similar numbers of viable bacteria $\left(3.2 \pm 0.5 \times 10^{9}\right.$ and $3.1 \pm 0.6 \times 10^{9}$, respectively). However, in TSB $1 \% \mathrm{G}$ grown biofilms, the number of culturable bacteria (c.f.u.) was significantly lower $\left(1.45 \pm 0.6 \times 10^{8}\right)$ as compared with TSB-grown biofilms $\left(13.4 \pm 1.2 \times 10^{8}\right)$; therefore, indicating higher amounts of viable but non-culturable (VBNC) bacteria within biofilms grown in excess glucose. These results indicated that excess glucose in the culture medium induced the accumulation of dormant bacteria within S. epidermidis biofilms.

\section{Effect of culture medium pH on S. epidermidis biofilm cell dormancy}

Excess glucose in the culture medium of Staphylococcus aureus (Rice et al., 2005), Streptococcus mutans (Renye et al., 2004) or Lactococcus lactis (Cook \& Russell, 1994) has already been shown to induce the accumulation of acidic compounds, with consequent decreases in the culture $\mathrm{pH}$. Similarly, we found that biofilms grown in TSB $1 \% \mathrm{G}$ accumulated lactic acid in the culture supernatant over time (Fig. 1b), which contributed to the detected decreases in the culture $\mathrm{pH}$ (Fig. 1c). Since acidic $\mathrm{pH}$ conditions have been described as inhibiting bacterial growth (Wijtzes et al., 1995), we evaluated whether the accumulation of dormant bacteria within the TSB $1 \% \mathrm{G}$ grown biofilms (low ratio c.f.u./viable bacteria) was related to the decrease in culture $\mathrm{pH}$. For that purpose, established biofilms were allowed to grow for an additional $24 \mathrm{~h}$ in TSB with an imposed acidic $\mathrm{pH}$ (TSB $\mathrm{pH} 5.0$ ) or in TSB $1 \% \mathrm{G}$ with maintained $\mathrm{pH}$ conditions (TSB $1 \% \mathrm{G}+\mathrm{HPO}_{4}{ }^{2-}$ ). We observed that biofilms grown in TSB pH 5.0 accumulated significantly higher amounts of dormant bacteria, when compared with biofilms grown in TSB only. However, buffering the accumulation of acidic compounds with hydrogen phosphate (TSB (a)

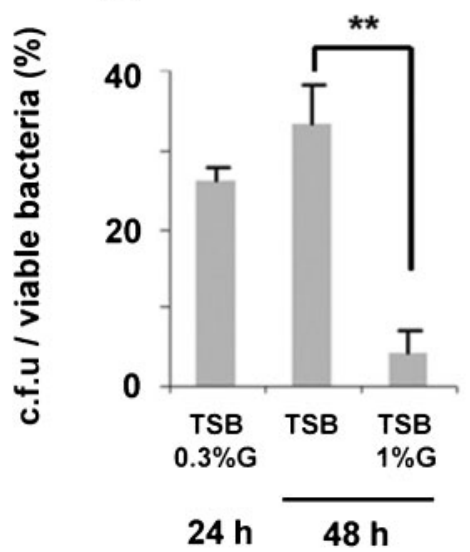

(b)

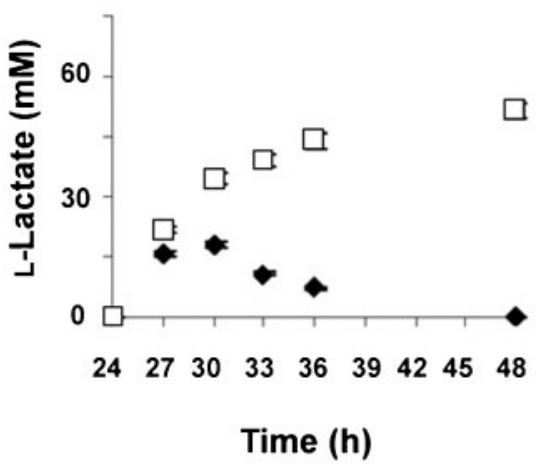

(c)

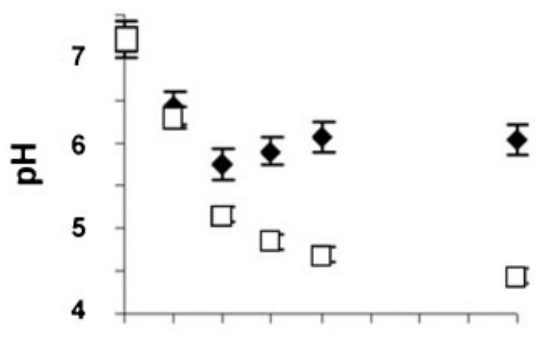

$\begin{array}{lllllllll}24 & 27 & 30 & 33 & 36 & 39 & 42 & 45 & 48\end{array}$

Time (h)

Fig. 1. Glucose induces cell dormancy in S. epidermidis biofilms. (a) The number of c.f.u. over the number of viable bacteria obtained from biofilms grown as indicated shown as percentages. Results are a representative example of four independent experiments. Statistically significant differences $\left(P<0.01\right.$, ANOVA) are indicated by asterisks $\left({ }^{\star *}\right)$. (b, c) Determination of (b) lactic acid accumulation and (c) culture medium pH over time in biofilms grown in TSB ( $\diamond$ ) or TSB $1 \%$ G ( $\square$ ). Results represent the mean value $\pm S D$ and are a representative example of three independent experiments. 
$\left.1 \% \mathrm{G}+\mathrm{HPO}_{4}{ }^{2-}\right)$ prevented the glucose-dependent accumulation of dormant bacteria, when compared with biofilms grown in TSB $1 \% \mathrm{G}$ only (data not shown). These results suggest that low culture $\mathrm{pH}$, a consequence of glucose metabolism and acid lactic accumulation, was responsible for inducing cell dormancy within S. epidermidis biofilms.

\section{Effect of calcium and magnesium on the glucose- induced cell dormancy}

Published studies have shown that supplementation of the culture medium with calcium (Delavechia et al., 2003; Macció et al., 2002; Watkin et al., 1997) or magnesium (Piddington et al., 2000) prevented the $\mathrm{pH}$-dependent inhibition of bacterial growth. We therefore supplemented both TSB and TSB 1\%G culture media with calcium $\left(\mathrm{Ca}^{2+}\right)$ and magnesium $\left(\mathrm{Mg}^{2+}\right)$, and evaluated their effect on the reported glucose-dependent cell dormancy. As shown in Fig. 2(a), supplementation of the TSB $1 \% \mathrm{G}$ culture medium with $\mathrm{Ca}^{2+}$ and $\mathrm{Mg}^{2+}$ prevented the accumulation of VBNC bacteria. This effect was found to be dependent on the acidic culture conditions, since a less marked effect was observed in TSB cultures (Fig. 2a). We further demonstrated that $\mathrm{Ca}^{2+}$ and $\mathrm{Mg}^{2+}$ did not interfere with the glucose metabolism since no differences were detected in glucose consumption (Fig. 2b) or lactic acid accumulation (Fig. 2c) in biofilm cultures grown in TSB $1 \% \mathrm{G}$ or TSB $1 \% \mathrm{G}+\mathrm{Ca}^{2+} / \mathrm{Mg}^{2+}$. Moreover, the concentration of these cations in TSB $1 \% \mathrm{G}+\mathrm{Ca}^{2+} / \mathrm{Mg}^{2+}$ culture medium was constant over time (data not shown), indicating that their effect relies on a generated high $\mathrm{Ca}^{2+}$ / $\mathrm{Mg}^{2+}$ extracellular concentration. The effect of excess glucose, $\mathrm{Ca}^{2+}$ and $\mathrm{Mg}^{2+}$ on modulating the proportions of VBNC bacteria within S. epidermidis biofilms was also observed when the S. epidermidis strains PE9, M187, JI6 and IE86 were used (Fig. 2d).

\section{Murine macrophage activation}

A published report showed that the shift from aerobic production of energy to fermentation in S. epidermidis was accompanied by a marked alteration in the bacterium's physiology, thought to induce the bacterium to enter a quiescent and less inflammatory mode of growth (Yao et al., 2005). In agreement with this report, we showed an association between fermentation (lactic acid production) and the accumulation of VBNC (dormant) bacteria in TSB $1 \% \mathrm{G}$ grown biofilms. However, the novelty presented in this study concerning S. epidermidis biofilms was the ability to modulate the proportions of dormant bacteria with (a)
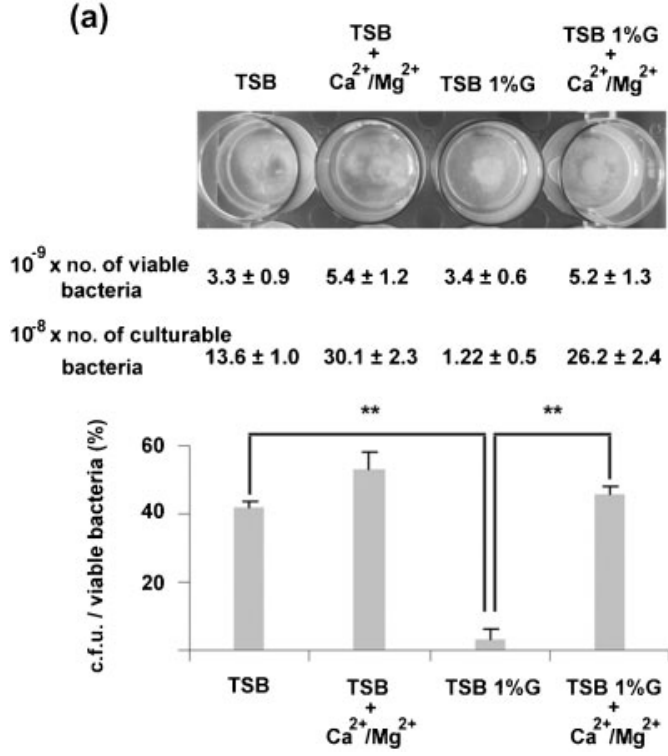

(b)

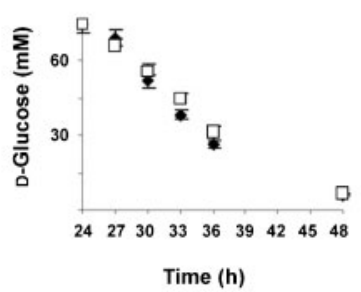

(c)

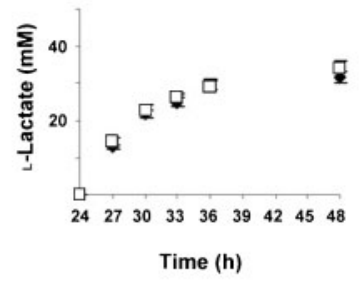

(d)

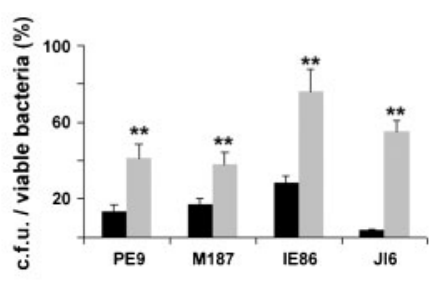

Fig. 2. Effect of calcium and magnesium on the glucose-induced cell dormancy. (a) The number of c.f.u. over the number of viable bacteria obtained from biofilms grown as indicated shown as percentages. Results are a representative example of four independent experiments. Statistically significant differences between groups $\left(P<0.01\right.$, ANOVA) are indicated by asterisks $\left({ }^{* *}\right)$. Numbers of viable and culturable bacteria within each biofilm grown as described are also presented. (b, c) Determination of (b) glucose consumption and (c) lactic acid accumulation over time in cultures of biofilms grown in TSB $1 \%$ G ( $\square$ ) or TSB $1 \% \mathrm{G}+\mathrm{Ca}^{2+} / \mathrm{Mg}^{2+}(\boldsymbol{\nabla})$. Results represent the mean value $\pm \mathrm{SD}$ and are a representative example of three independent experiments. (d) The number of c.f.u. over the number of viable bacteria obtained from S. epidermidis PE9, M187, JI6 and IE86 biofilms grown in TSB $1 \% \mathrm{G}$ (black bars) or TSB $1 \% \mathrm{G}+\mathrm{Ca}^{2+} / \mathrm{Mg}^{2+}$ (grey bars) shown as percentages. Results are a representative example of two independent experiments. Statistically significant differences between groups $(P<0.01$, ANOVA) are indicated by asterisks $\left.{ }^{* *}\right)$. 
(a)

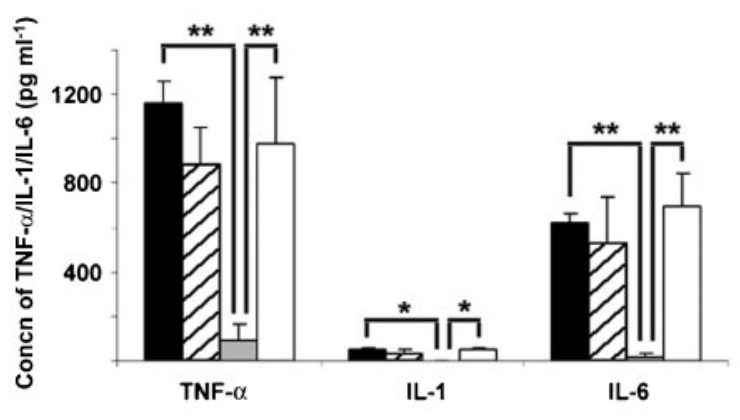

(b)

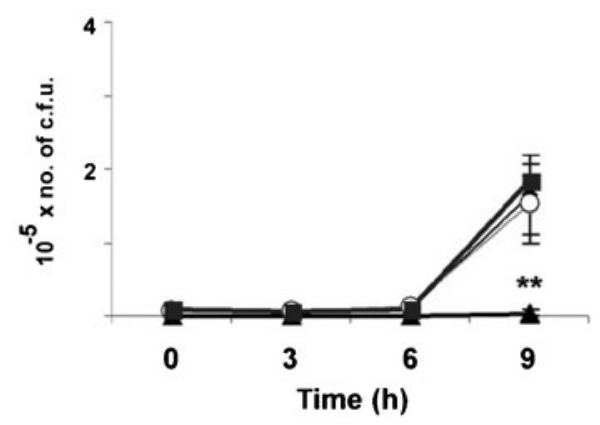

Fig. 3. Effect of cell dormancy on BMDM activation. (a) Concentrations of TNF- $\alpha, \mathrm{IL}-1$ and IL-6 in cell culture supernatants of BMDMs after $9 \mathrm{~h}$ incubation with $1 \times 10^{4}$ live bacteria obtained from $S$. epidermidis biofilms grown as indicated. Black bars, TSB; hatched bars, TSB $+\mathrm{Ca}^{2+} / \mathrm{Mg}^{2+}$; grey bars, TSB $1 \% \mathrm{G}$; white bars, TSB $1 \% \mathrm{G}+\mathrm{Ca}^{2+} / \mathrm{Mg}^{2+}$. (b) Numbers of c.f.u. in BMDM culture supernatants determined at $3 \mathrm{~h}$ intervals after bacterial challenge. Results are a representative example of three independent experiments. $\downarrow$ TSB; $\bigcirc$, TSB $+\mathrm{Ca}^{2+} / \mathrm{Mg}^{2+} ; \mathbf{\Delta}$, TSB $1 \% \mathrm{G} ; \mathbf{\square}, \mathrm{TSB} 1 \% \mathrm{G}+\mathrm{Ca}^{2+} / \mathrm{Mg}^{2+}$. The statistically significant difference between the TSB $1 \% \mathrm{G}$ inoculum and the other inocula $\left(P<0.01\right.$, ANOVA) is indicated by asterisks $\left(^{* *}\right)$.

extracellular $\mathrm{Ca}^{2+}$ and $\mathrm{Mg}^{2+}$. The presence of these cations in the TSB $1 \% \mathrm{G}$ culture medium prevented the $\mathrm{pH}$-dependent accumulation of dormant bacteria within biofilms despite low $\mathrm{pH}$ cultures still being achieved. Based on this observation, we compared the inflammatory potential of bacteria obtained from S. epidermidis biofilms with high and low proportions of dormant cells. Since $S$. epidermidis has been shown elsewhere to induce cytokine production by human peripheral blood mononuclear cells in vitro (Härtel et al., 2008; Megyeri et al., 2002; Stuyt et al., 2003), we evaluated the ability of different bacterial inocula, obtained from biofilms grown in TSB, TSB $+\mathrm{Ca}^{2+} / \mathrm{Mg}^{2+}$, TSB $1 \% \mathrm{G}$, or TSB $1 \% \mathrm{G}+\mathrm{Ca}^{2+} / \mathrm{Mg}^{2+}$, to induce the production of pro-inflammatory cytokines by BMDMs. As shown in Fig. 3(a), lower levels of TNF- $\alpha$, IL-1 and IL-6 were detected in the supernatants of BMDM challenged with the inoculum containing higher proportions of VBNC bacteria (TSB $1 \% \mathrm{G}$ ), as compared with the other inocula assessed. The above reported effect of $\mathrm{Ca}^{2+}$ and $\mathrm{Mg}^{2+}$ in preventing the glucose-induced cell dormancy was also shown to affect the extent of BMDM activation as higher cytokine levels were detected in culture supernatants of BMDMs challenged with the TSB $1 \% \mathrm{G}+\mathrm{Ca}^{2+} / \mathrm{Mg}^{2+}$ inoculum as compared with the TSB $1 \% \mathrm{G}$ inoculum (Fig. 3a). We have also evaluated bacterial growth in the BMDM cultures infected with the different inocula. As shown in Fig. 3(b),
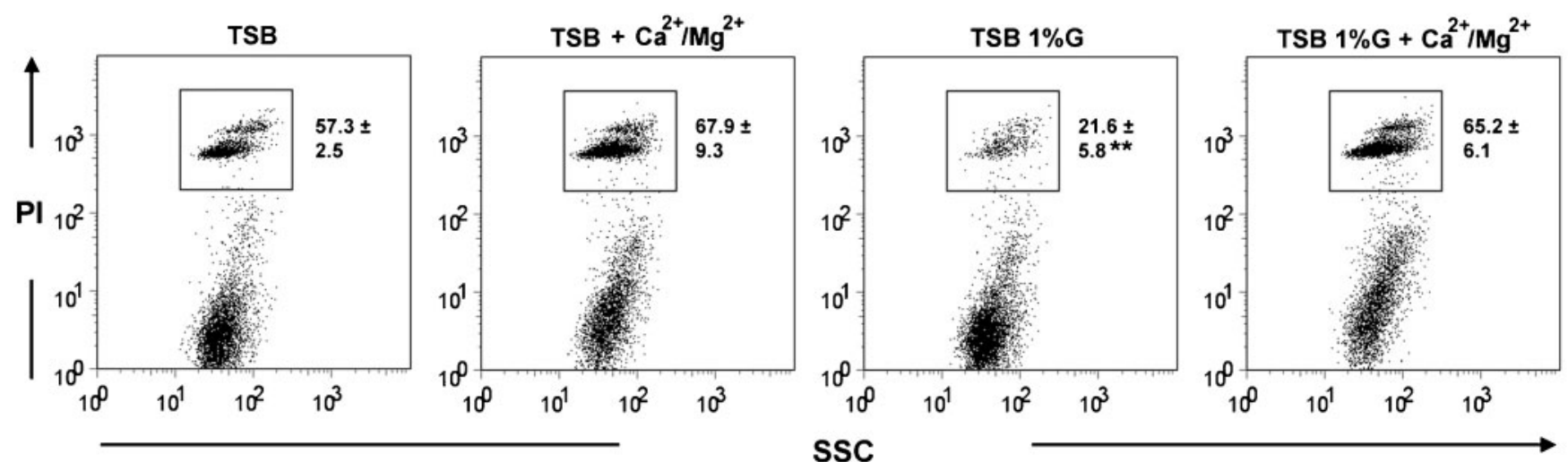

Fig. 4. Evaluation by flow cytometric analysis of BMDM death following $2 \mathrm{~h}$ incubation with intact $S$. epidermidis biofilms grown as indicated. BMDMs were discriminated from bacteria according to the SSC parameter. Dot plots are representative examples of two independent experiments. The mean proportion \pm SD of dead BMDMs $\left(\mathrm{PI}^{+}\right)$are shown within the dot plots. The statistically significant difference between the TSB $1 \% \mathrm{G}$ inoculum and the other inocula $(P<0.01, \mathrm{ANOVA})$ is indicated by asterisks $\left(^{* *}\right)$. 

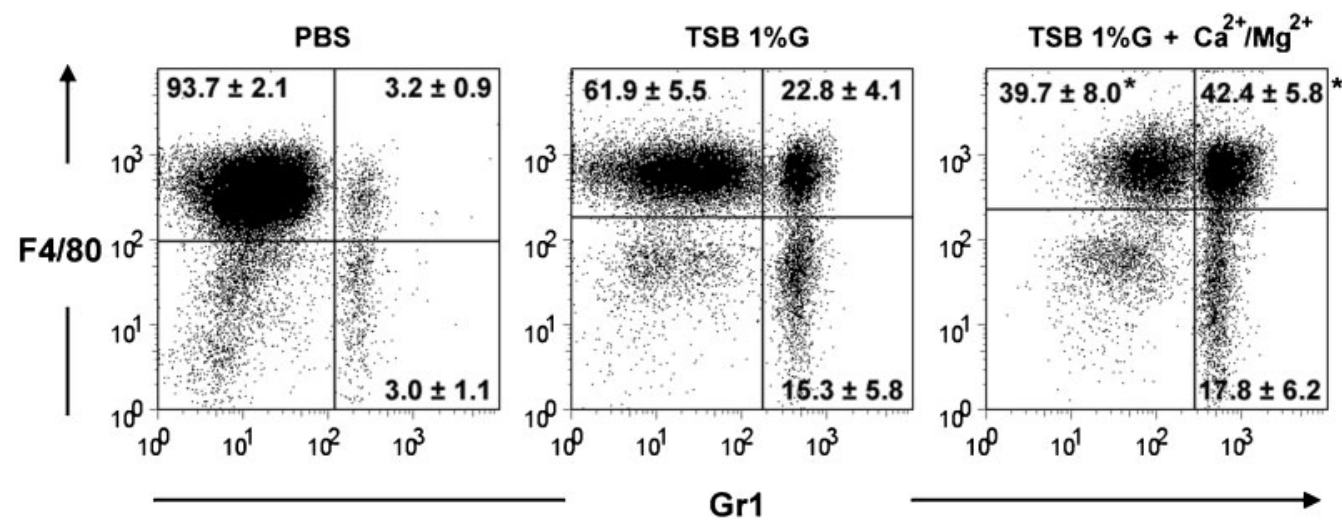

Fig. 5. Effect of cell dormancy on peritoneal macrophage activation. Flow cytometric analysis of peritoneal cell exudates after intra-peritoneal challenge with $5 \times 10^{5} \mathrm{~S}$. epidermidis bacteria obtained from biofilms grown in TSB $1 \% \mathrm{G}$ or TSB $1 \% \mathrm{G}+\mathrm{Ca}^{2+} / \mathrm{Mg}^{2+}$. Dot plots are representative examples of two independent experiments ( $n=4$ per group). The proportions $\pm \mathrm{SD}$ of non-activated macrophages $\left(\mathrm{F} 4 / 80^{+} \mathrm{Gr} 1^{-}\right)$, activated macrophages $\left(\mathrm{F} 4 / 80^{+} \mathrm{Gr} 1^{+}\right)$or macrophages at a final stage of activation $\left(\mathrm{F} 4 / 80^{-} \mathrm{Gr}^{+}\right)$are shown within the dot plots. Cells with typical FSC and SSC parameters for lymphoid cells were excluded from the analysis. The statistically significant difference between the TSB $1 \% \mathrm{G}$ and $\mathrm{TSB} \% \mathrm{G}+\mathrm{Ca}^{2+} /$ $\mathrm{Mg}^{2+}$ groups $(P<0.05$, ANOVA $)$ is indicated by an asterisk $\left(^{*}\right)$.

significantly lower numbers of c.f.u. were observed over time in the cultures challenged with the TSB $1 \% \mathrm{G}$ inoculum. This suggests an association between the observed differences in cytokine production and the reported differences in bacterial culturability.

We further attempted to evaluate cytokine production by BMDMs incubated with intact S. epidermidis biofilms. However, BMDMs were found to die rapidly when added to intact biofilms, preventing a significant accumulation of cytokines in culture supernatants. Nevertheless, evaluation of BMDM death, by assessing PI incorporation with flow cytometry, showed decreased cell death in BMDMs incubated with TSB $1 \% \mathrm{G}$ grown biofilms, as compared with the other biofilms assessed (Fig. 4). This result further suggests that differences in the biofilm physiological state may lead to different interactions with host immune cells.

Macrophage activation was also assessed after intraperitoneal challenge with bacteria obtained from biofilms grown in TSB $1 \% \mathrm{G}$ or TSB $1 \% \mathrm{G}+\mathrm{Ca}^{2+} / \mathrm{Mg}^{2+}$. Based on the surface expression of $\mathrm{F} 4 / 80, \mathrm{Gr} 1$ and MHC class II molecules (MHC-II), and cell size (high FSC level), peritoneal macrophages were defined in three different subsets: nonactivated macrophages $\left(\mathrm{F} 4 / 80^{+} \mathrm{Gr}^{-} \mathrm{MHC}^{-} \mathrm{II}^{\mathrm{INT}} \mathrm{FSC}^{\mathrm{INT}}\right)$, activated macrophages $\left(\mathrm{F} 4 / 80^{+} \mathrm{Grl}^{+} \mathrm{MHC}-\mathrm{II}^{\mathrm{INT}} \mathrm{FSC}^{\mathrm{HIGH}}\right)$ (Mayhew \& Williams, 1973; Mordue \& Sibley, 2003) and macrophages at a final activation stage ( $\mathrm{F} 4 / 80^{-} \mathrm{Gr} 1^{+} \mathrm{MHC}-$ $\mathrm{II}^{\mathrm{HIGH}} \mathrm{FSC}^{\mathrm{INT}}$ ) (Ezekowitz \& Gordon, 1982; Ezekowitz et al., 1981). As shown in Fig. 5, higher proportions of nonactivated macrophages $\left(\mathrm{F} 4 / 80^{+} / \mathrm{Gr}^{-}\right)$and lower proportions of activated macrophages $\left(\mathrm{F} 4 / 80^{+} / \mathrm{Gr}^{+}\right)$were found in the peritoneal cavities of mice challenged with the TSB $1 \% \mathrm{G}$ inoculum, further suggesting a lower inflammatory effect of the inocula enriched in dormant bacteria.

\section{Concluding remarks}

It is well established that environment plays an important role in modulating the biofilm physiological state (Stewart \& Franklin, 2008). Despite the difficulty in predicting the environmental conditions where infectious biofilms are grown, glucose in the oral cavity (Lemos et al., 2005), blood (Croes et al., 2009) or peritoneal dialysis fluid (Dasgupta et al., 1988) make this carbon source an important factor in determining plaque biofilm development or biofilm establishment in intravascular or peritoneal dialysis catheters. In vitro, glucose is a wellknown stimulus inducing the biofilm mode of growth (Mack et al., 1992; Yao et al., 2005), reinforcing the role of this carbon source in biofilm physiology. In this study we have shown that glucose indirectly modulates the $S$. epidermidis biofilm physiological state regarding the amounts of dormant bacteria. Moreover, we associate the dormant bacteria content of biofilm with its inflammatory potential as these cells were found to induce a lower macrophage activation. The herein reported modulation of the dormant bacteria content of biofilms highlights that the interaction of biofilms with the host immune response may depend on their physiological state. This, in turn, may account for the different clinical manifestations of biofilmassociated infections.

\section{ACKNOWLEDGEMENTS}

The authors acknowledge the technical assistance of Ângela Magalhães. This work was supported by Fundação para a Ciência e a Tecnologia (FCT) FCOMP-01-0124-FEDER-014309 (PTDC/BIA-MIC/113450/ 2009). Filipe Cerca, Ângela França and Elva Bonifácio Andrade were supported by FCT fellowships SFRH/BD/27638/2006, SFRH/BD/ $62359 / 2009$ and FRH/BD/38380/2007, respectively. The funders had 
no role in study design, data collection and analysis, decision to publish, or preparation of the manuscript.

\section{REFERENCES}

Ben-Amor, K., Heilig, H., Smidt, H., Vaughan, E. E., Abee, T. \& De Vos, W. M. (2005). Genetic diversity of viable, injured, and dead fecal bacteria assessed by fluorescence-activated cell sorting and 16S rRNA gene analysis. Appl Environ Microbiol 71, 4679-4689.

Brown, M. R. W., Allison, D. G. \& Gilbert, P. (1988). Resistance of bacterial biofilms to antibiotics: a growth-rate related effect? J Antimicrob Chemother 22, 777-780.

Cerca, N., Pier, G. B., Vilanova, M., Oliveira, R. \& Azeredo, J. (2004). Influence of batch or fed-batch growth on Staphylococcus epidermidis biofilm formation. Lett Appl Microbiol 39, 420-424.

Cook, G. M. \& Russell, J. B. (1994). The effect of extracellular pH and lactic acid on $\mathrm{pH}$ homeostasis Lactococcus lactis and Streptococcus bovis. Curr Microbiol 28, 165-168.

Costerton, J. W., Stewart, P. S. \& Greenberg, E. P. (1999). Bacterial biofilms: a common cause of persistent infections. Science 284, 13181322.

Costerton, W., Veeh, R., Shirtliff, M., Pasmore, M., Post, C. \& Ehrlich, G. (2003). The application of biofilm science to the study and control of chronic bacterial infections. J Clin Invest 112, 1466-1477.

Croes, S., Deurenberg, R. H., Boumans, M.-L., Beisser, P. S., Neef, C. \& Stobberingh, E. E. (2009). Staphylococcus aureus biofilm formation at the physiologic glucose concentration depends on the $S$. aureus lineage. BMC Microbiol 9, 229.

Dasgupta, M. K., Lam, K., Ulan, R. A., Bettcher, K. B., Burns, V., Tyrrell, D. L., Dossetor, J. B. \& Costerton, J. W. (1988). An extracorporeal model of biofilm-adherent bacterial microcolony colonization for the study of peritonitis in continuous ambulatory peritoneal dialysis. Am J Nephrol 8, 118-122.

Delavechia, C., Hampp, E., Fabra, A. \& Castro, S. (2003). Influence of $\mathrm{pH}$ and calcium on the growth, polysaccharide production and symbiotic association of Sinorhizobium meliloti SEMIA 116 with alfalfa roots. Biol Fertil Soils 38, 110-114.

Ezekowitz, R. A. \& Gordon, S. (1982). Down-regulation of mannosyl receptor-mediated endocytosis and antigen F4/80 in Bacillus Calmette-Guérin-activated mouse macrophages. Role of T lymphocytes and lymphokines. J Exp Med 155, 1623-1637.

Ezekowitz, R. A., Austyn, J., Stahl, P. D. \& Gordon, S. (1981). Surface properties of Bacillus Calmette-Guérin-activated mouse macrophages. Reduced expression of mannose-specific endocytosis, Fc receptors, and antigen F4/80 accompanies induction of Ia. J Exp Med 154, 60-76.

Fux, C. A., Costerton, J. W., Stewart, P. S. \& Stoodley, P. (2005). Survival strategies of infectious biofilms. Trends Microbiol 13, 34-40.

Härtel, C., Osthues, I., Rupp, J., Haase, B., Röder, K., Göpel, W., Herting, E. \& Schultz, C. (2008). Characterisation of the host inflammatory response to Staphylococcus epidermidis in neonatal whole blood. Arch Dis Child Fetal Neonatal Ed 93, F140-F145.

Kaprelyants, A. S. \& Kell, D. B. (1993). Dormancy in stationary-phase cultures of Micrococcus luteus: flow cytometric analysis of starvation and resuscitation. Appl Environ Microbiol 59, 3187-3196.

Kaprelyants, A. S., Gottschal, J. C. \& Kell, D. B. (1993). Dormancy in nonsporulating bacterial. FEMS Microbiol Rev 104, 271-286.

Lemos, J. A. C., Abranches, J. \& Burne, R. A. (2005). Responses of cariogenic streptococci to environmental stresses. Curr Issues Mol Biol 7, 95-107.
Lewis, K. (2007). Persister cells, dormancy and infectious disease. Nat Rev Microbiol 5, 48-56.

Macció, D., Fabra, A. \& Castro, S. (2002). Acidity and calcium interaction affect the growth of Bradyrhizobium sp. and the attachment to peanut roots. Soil Biol Biochem 34, 201-208.

Mack, D., Siemssen, N. \& Laufs, R. (1992). Parallel induction by glucose of adherence and a polysaccharide antigen specific for plasticadherent Staphylococcus epidermidis: evidence for functional relation to intercellular adhesion. Infect Immun 60, 2048-2057.

Mayhew, T. M. \& Williams, M. A. (1973). The mass and size of normal and activated macrophages-studies with a scanning interferometer. Experientia 29, 80-81.

Megyeri, K., Mándi, Y., Degré, M. \& Rosztóczy, I. (2002). Induction of cytokine production by different staphylococcal strains. Cytokine 19, 206-212.

Mordue, D. G. \& Sibley, L. D. (2003). A novel population of Gr-1 ${ }^{+}$activated macrophages induced during acute toxoplasmosis. J Leukoc Biol 74, 1015-1025.

O'Toole, G., Kaplan, H. B. \& Kolter, R. (2000). Biofilm formation as microbial development. Annu Rev Microbiol 54, 49-79.

Piddington, D. L., Kashkouli, A. \& Buchmeier, N. A. (2000). Growth of Mycobacterium tuberculosis in a defined medium is very restricted by acid $\mathrm{pH}$ and $\mathrm{Mg}^{2+}$ levels. Infect Immun 68, 4518-4522.

Qu, Y., Daley, A. J., Istivan, T. S., Rouch, D. A. \& Deighton, M. A. (2010). Densely adherent growth mode, rather than extracellular polymer substance matrix build-up ability, contributes to high resistance of Staphylococcus epidermidis biofilms to antibiotics. J Antimicrob Chemother 65, 1405-1411.

Renye, J. A., Jr, Piggot, P. J., Daneo-Moore, L. \& Buttaro, B. A. (2004). Persistence of Streptococcus mutans in stationary-phase batch cultures and biofilms. Appl Environ Microbiol 70, 6181-6187.

Rice, K. C., Nelson, J. B., Patton, T. G., Yang, S.-J. \& Bayles, K. W. (2005). Acetic acid induces expression of the Staphylococcus aureus cidABC and $\operatorname{lrg} A B$ murein hydrolase regulator operons. J Bacteriol 187, 813-821.

Saegeman, V. S. M., De Vos, R., Tebaldi, N. D., Van der Wolf, J. M., Bergervoet, J. H. W., Verhaegen, J., Lismont, D., Verduyckt, B. \& Ectors, N. L. (2007). Flow cytometric viability assessment and transmission electron microscopic morphological study of bacteria in glycerol. Microsc Microanal 13, 18-29.

Shen, Y., Stojicic, S. \& Haapasalo, M. (2010). Bacterial viability in starved and revitalized biofilms: comparison of viability staining and direct culture. J Endod 36, 1820-1823.

Shleeva, M. O., Bagramyan, K., Telkov, M. V., Mukamolova, G. V., Young, M., Kell, D. B. \& Kaprelyants, A. S. (2002). Formation and resuscitation of "non-culturable" cells of Rhodococcus rhodochrous and Mycobacterium tuberculosis in prolonged stationary phase. Microbiology 148, 1581-1591.

Stewart, P. S. \& Franklin, M. J. (2008). Physiological heterogeneity in biofilms. Nat Rev Microbiol 6, 199-210.

Stuyt, R. J. L., Kim, S.-H., Reznikov, L. L., Fantuzzi, G., Novick, D., Rubinstein, M., Kullberg, B. J., Van der Meer, J. W. M., Dinarello, C. A. \& Netea, M. G. (2003). Regulation of Staphylococcus epidermidisinduced IFN-rin whole human blood: the role of endogenous IL-18, IL-12, IL-1, and TNF. Cytokine 21, 65-73.

Vuong, C. \& Otto, M. (2002). Staphylococcus epidermidis infections. Microbes Infect 4, 481-489.

Watkin, E. L. J., O’Hara, G. W. \& Glenn, A. R. (1997). Calcium and acid stress interact to affect the growth of Rhizobium leguminosarum bv. trifolii. Soil Biol Biochem 29, 1427-1432. 
Wijtzes, T., De Wit, J. C., In Huis, Van't, R. \& Zwietering, M. H. (1995). Modelling bacterial growth of Lactobacillus curvatus as a function of acidity and temperature. Appl Environ Microbiol 61, 2533-2539.

Wolcott, R. D. \& Ehrlich, G. D. (2008). Biofilms and chronic infections. JAMA 299, 2682-2684.
Yao, Y., Sturdevant, D. E. \& Otto, M. (2005). Genomewide analysis of gene expression in Staphylococcus epidermidis biofilms: insights into the pathophysiology of S. epidermidis biofilms and the role of phenolsoluble modulins in formation of biofilms. J Infect Dis 191, 289298. 